calculations necessary to the revision of Le Verrier's tables of Jupiter.

2000 francs to M. Bordmann, for the completion of his stellar photometer.

2000 francs to M. Quidor, for assistance in the publication of his memoir on the external morphology of the parasitic copepods.

\section{SEX RELATIONSHIP.}

PERHAPS one of the most subtle and interesting problems of life is the numerical relationship of sex and its influence on the body politic.

It has always been something of a puzzle why the proportion of each kind, apparently with little or no underlying reason, is produced in the right numbers. 'The argument that if such were not the case the particular species would not survive does not reveal to us the methods by which this object has been achieved by nature. That some mechanism must exist by means of which, within certain limits, the number of males and females born is regulated, is proved by the facts of history, where we have numerous examples of wars and other social upheavals where males have largely suffered, and yet within an apparently short period of time, as measured by such events, a balance has been again re-established. The sex equilibrium may be compared to that of a gyroscope, where the greater the disturbance of position the greater is the force tending to re-establish its natural stand whilst in motion. Nature in her methods never does anything exactly, but approaches an object by establishing lateral control, which guides her on her way, should any deviation occur. Thus she does not proceed along a straight line, but is continually oscillating to either side. Her progress may very well be likened to that of an inebriated person in search of his dwelling. All that can be said is that he has a tendency homewards.

The facts regulating sex must be something of the same type, and are such that the greater the oscillation in any one direction the greater must be the restraining force invoked to curb or neutralise the movement. All such movements have an inertia, and consequently, like a pendulum, pass the middle line and establish a negative phase. The history of any race in its sex composition would show us that such oscillations have occurred throughout time, modified, no doubt, in their regular sequence by such factors as wars and famine. These oscillations of sex balance have brought with them certain changes and movements in the people themselves; an excess of males would naturally tend to produce war, either civil or foreign, whilst a superfluity of females is easily associated with upheavals in the domestic polity of the community. There is no doubt that, could we trace the history of the world, or any section of it, we should see that man simply reacts to certain variations which are inevitable sequences in the establishment of this balance. Are there at present any indications of the methods upon which, or factors by which, this state is maintained? As is usually found, "truth is simple," and so the workings of nature, when once discovered, are easily understood. The sex constitution of our population, upon which such mighty issues depend, appears to obtain its regulating force from a very simple factor, and apparently is correlated with age only.

At the present time the sex balance is as follows:At birth the ratio of males to females is about IO3O to I000; at the fifth year, owing to deaths amongst the males, the balance is equal; from the fifth to the fifteenth year the mortality amongst the females is slightly higher than amongst the males, but from that time onwards the females relatively increase. If we take the male as a few years older than the female for the purpose of mating, then the balance is disturbed further still. The result of this is to produce in a community a section of women who cannot possibly perform that function for which they were fashioned. Their energies are naturally directed into other spheres, as evidence of which we see the revival of the movement for political recognition. The agitation is no new one, and apparently is dependent for its strength and virility on the position of the sex pendulum. If the pre- sent female oscillation has not yet reached its zenith the agitation will continue; if the reverse is happening, as there is reason to believe to be the case, then the present movement, after certain bursts of rejuvenescence, should slowly subside, to be again resurrected at some future epoch in the history of the world.

The following table gives the relationship of the age of the mother to the sex of the child :-

(Taken from an Inquiry into Birth Conditions in the Torn of Middlesbrough.)

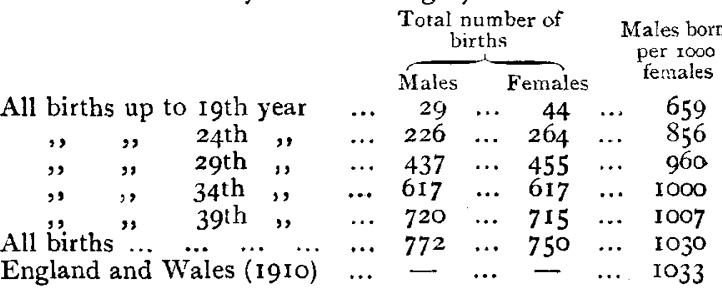

If taken between the stated ages the figures are as follows :-

\begin{tabular}{|c|c|c|c|c|c|c|}
\hline \multirow[b]{3}{*}{ Up to I 9 th year } & & \multicolumn{3}{|c|}{$\begin{array}{l}\text { Total number in } \\
\text { each period }\end{array}$} & \multirow{2}{*}{\multicolumn{2}{|c|}{$\begin{array}{l}\text { Males born } \\
\text { per rooo } \\
\text { females in } \\
\text { each period }\end{array}$}} \\
\hline & & Males & & Females & & \\
\hline & & 29 & $\ldots$ & 44 & $\ldots$ & 659 \\
\hline From 20 th to 24 & ear inclusive & 197 & $\ldots$ & 220 & $\ldots$ & 895 \\
\hline $25^{\text {th }}$ & & $2 I I$ & $\ldots$ & I9I & $\ldots$ & 1105 \\
\hline , 3oth , 34th & $"$ & 180 & $\cdots$ & 162 & $\ldots$ & IIII \\
\hline $34^{\text {th }}$ year and over & $\ldots$ & I 55 & $\ldots$ & 133 & $\ldots$ & I 165 \\
\hline
\end{tabular}

It is seen that, as a matter of fact, the tendency to produce females over males is present in young mothers; at more mature ages there is an excess of males. We can easily see how a self-regulating balance is established, depending upon this fact. In a state of society in which females are scarce they naturally, owing to demand, mate early in life, and tend thereby to reproduce an excess of their own kind (females), thus neutralising the state which recently existed. On the other hand, should the males be in the minority, the females will mate at more mature ages, at any rate at ages of twenty-five and above as is at present, in which circumstance an excess of males is produced. We see, therefore, that the natural tendency at the present time is to neutralise the female excess. We may possibly look upon ourselves at the present moment as being at the zenith of a female oscillation, and as time progresses, helped probably by a saving of infantile life, a more numerical equality of sex will be established.

The relationship of the age of the father to the sex of the child is much the same as the mother, and where disparity in age occurs the influences may neutralise each other, so that with a mother of about twenty vears and a father of about thirty years the chance of a boy or a girl should be about as equal as nature can make such a problem. Education is attempting to teach the inhibition of self, and thus delaying the age of marriage, so that the preponderance of male births should go on increasing. If the present rate of progress is maintained, and allowing for the greater mortality of the male infant over the female, an average marriage rate of between twenty-seven and twenty-eight years should produce a population in which the males are at all periods in excess of the females. R. J. EWART.

\section{AVIATORS AND SQUALLS.}

$\mathrm{N}$ looking through the now formidable list of fatalities which mark the progress, and the dangers, of aviation, the reader is often struck by the number of accidents where the reason for the capsize of the machine is not apparent. "Holes in the air" is the explanation frequently tendered, but it seems more than probable that sudden gusts, or squalls, at critical moments may be the real factors causing the trouble. For this reason an article by M. Durand-Gréville in the December (I9ro) number of the Bulletin de la Société astronomique de France is of interest.

M. Durand-Gréville proposes a system of warnings of No. 2 I 49 , VOL. 85] 
grains and coups de vent which would inform the airman of the approach of grave risks should he attempt an ascent until the squall has passed. So far back as $1892 \mathrm{M}$. Durand-Gréville made the suggestion to meteorologists in a menoir entitled "Les Grains et les Orages," which appeared in the Annales du Bureau central meteorologique de France. This memoir showed that the isochronic lines markins the commencement of storms corresponded with much longer isochrones of squalls. The name ruban de grain was attached to a more or less sinuous band extending from near the centre to the circumference of a depression. This band is often 1000-r $500 \mathrm{~km}$. (625-940 miles) long, and in its interior the wind is very strong, and often accompanied by precipitation. The advent of the squall is generally marked by a gentle south-west wind veering with startling suddenness and violence to the north-west, masses of cloud come up rapidly from the west, and frequently heavy thunder is heard. All these phenomena occur suddenly and practically simultaneously, so that the passing of the squall is easily and definitely observed.

M. Durand-Greville's proposal is that from those stations first passed over, telegraphic warnings should be immediately dispatched to centres lying eastwards in the subsequent path of the disturbance. Numerous experiments have demonstrated the feasibility and utility of the scheme. Stations west of Paris have sent messages announcing squalls which have subsequently passed over that city at the predicted time.

On the occasion of the great Aëronautical Congress at Frankfort during 1909 , the plan was tried by M. Linke, director of the meteorological station there. Fifty-five observers within a radius of $150 \mathrm{~km}$. were asked to notify the director of any squall which passed over their separate stations, and M. Durand-Gréville states that, "save in one or two cases, all the storms which visited Frankfort during this period were known to M. Linke more than an hour in advance."

M. Durand-Gréville points out that the expense to any body which undertook the organisation of the warnings would be almost negligible as compared with the money expended in prizes awarded to aviators, not to mention the much greater cost of machines, \&c., and the lamentable sacrifice of human life which might, at least to some extent, be obviated. The ordinary forecasts and warnings issued by the various national meteorological offices are far too general to be of use in this regard, but special services might be instituted, as a trial, by some of the societies especially interested in aëronautical matters.

\section{TEMPERATURE OF THE UPPER AIR.}

M. M. RYKACHEF has worked out the results of 1. balloon ascents at Pavlovsk, Kuchino near Moscow, Pavlovsk, thirty-two at Kuchino, and twelve at Olchedaief, some of which attained a height of 12 kilometres. Wilh regard to the yearly means, the temperature at Pavlovsk was up to $9 \mathrm{~km}$. lower than at Kuchino, the differences increasing up to 3 to $3.5 \mathrm{~km}$., and then diminishing. At $9 \mathrm{~km}$. they change sign, increasing up to a maximum of about $4^{\circ} \mathrm{C}$. between 10.5 and $12 \mathrm{~km}$. The difference of temperature between Pavlovsk and Nizhni Olchedaief is much greater, diminishes up to ro $\mathrm{km}$., where it changes sign, and attains a maximum of $I^{\circ}$ between $I I$ and $I 2 \mathrm{~km}$. A marked diminution in the fall of temperature takes place at a lower height in Pavlovsk than in Kuchino, and at Kuchino than at Olchedaief, the heights being 9.5 , 0.8 , and $10.8 \mathrm{~km}$. respectively. The temperature of the isothermic layers is highest at Pavlovsk and lowest at Kuchino. These variations may be explained by the differences of latitude, Pavlovsk being situated at about $60^{\circ}$, Kuchino $56^{\circ}$, and Nizhni Olchedaief $48^{\circ}$, while Pavlovsh is more exposed to the mild influence of a sea climate than the other two places.

At Nizhni Olchedaief the ascents were too few to deduce any satisfactory conclusions with regard to seasonal variations. At Pavlovsk the temperature at all seasons from the ground up to 8.5 to $9 \mathrm{~km}$. was lower than at Kurchino, except that in winter the temperature up to 500 metres was higher, which result accords with the readings taken on the ground for a series of years. The difference of NO. 2 I 49, VOL. 85] temperature in winter, spring, and autumn shows a marked increase at about 2.5 to $3 \mathrm{~km}$., changes sign at 8.5 to $9 \mathrm{~km}$., and rapidly increases to the isothermic layers, where the temperature is lower at Kuchino than at Pavlovsk. In summer the difference decreases continually up to $9.5 \mathrm{~km}$., and then changes sign and increases. The height where the fall in the temperature becomes in significant is lower in all seasons at Pavlovsk than at Kuchino, except in spring, when it is about $10 \mathrm{~km}$. at both stations.

The temperature of the isothermal region is markedly lower at Kuchino. In the curve of monthly means is seen a retardation of the maximum in the higher layers of air In the lower atmosphere the maximum occurs in July both at Pavlovsk and Kuchino, but at greater heights it occurs in August, the change taking place at a height of $2.5 \mathrm{~km}$. at Kuchino and at $4.5 \mathrm{~km}$. at Pavlovsk. At $9 \mathrm{~km}$. the maximum returns to July. The minimum exhibits somewhat similar variations. Amplitudes and gradients mean changes of temperature with elevation in cyclone and anticyclones, \&c., are also discussed, with numerous tables and diagrams, in an article published in the Bulletin of the Imperial Academy of Sciences of St. Petersburg, No. 7, I910.

\section{THE INCENSE-ALTAR OF APHRODITE AT} PAPHOS.

A $\mathrm{N}$ interesting article by Dr. Max Ohnefalsch-Richter appears in Globus of November 17 (xcviii., pp. 293-7), in which he brings forward data to prove his earlier supposition that the first site of Paphos was in the neighbourhood of Randi, in Cyprus. Certain inscriptions from this vicinity showed that Aphrodite, "the unconquerable," sender of Spring, was worshipped, and that an ancient incense-altar had existed there. The block containing the most important inscription is held by Prof. Richard Meister, of Leipzig, to belong to an incense-altar, and he adds that the incense-altar of Aphrodite at Paphos (Homer, VIII., 362; Homeric Hymns, IV., 59) was famous from earliest times.

Last August Dr. Ohnefalsch-Richter was able to identify a semi-subterranean side-chamber in the rock connected with this altar, whence had come the inscribed incensebowls which Prof. Meister has been deciphering. Dr. Zahn's excavations in the chamber have brought to light some half-dozen further inscriptions in the Paphian script, and he has made a number of valuable discoveries on the hill-side below, among them phalli which again played an important part in the Paphian Aphrodite-worship. The cult carried on on the hill consisted in making incense offerings, as described by Homer; in Dr. Zahn's opinion images were not used originally. A clay statue of about life-size was, however, found in the middle of the altarchamber, the style indicating a date about 600 B.c. The article concludes:- "We must wait to see what Prof. Meister will make of the hundred and more inscriptions discovered. As yet everything supports my surmise that on the hill of the incense-altar at Randi, not only an incense-altar of Aphrodite Paphia stood, but the mos: famous, the Homeric, incense-altar of Aphrodite of Paphos.'

Early in the article the writer refers to ten inscribed stones from Randi "from secret, prohibited excavations." which were fortunately purchased by someone who generously presented them to the Cyprus Museum. This is additional evidence, if such be required, of the urgent necessity for strong measures by the Government for the repression of illicit traffic in objects of archæological interest in this island and elsewhere.

\section{AIMS OF ASTRONOMY OF PRECISION. ${ }^{1}$}

THE science of precise physical measurement is one which does not readily appeal to those not immediately concerned, either with the methods or results. An authoritative statement that the sun's distance from the earth is $92,880,000$ miles may excite wonder, but scarcely more than will the statement that it is approximately

1 From the presidential address delivered before the Royal Society of South Africa on April 20, 1910, by S. S. Hough, F. R S. Published in the Transactions of the Society, vol. ii., part i. 